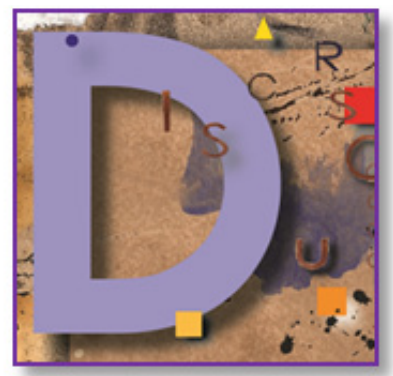

\title{
EXPRESSÕES MULTIMODAIS DE ANUNCIOS PUBLICITÁRIOS PARA A REPRESENTAÇÃO DO FEMININO: IMPLÍCITOS E CONTEXTOS
}

\author{
Regina Célia Pagliuchi da Silveira* (PUC/SP)
}

Este artigo, situado na Análise Crítica do Discurso tem por tema a representação do feminino em textos multimodais publicitários, objetivando examinar, na composição textual do verbal e com o visual (imagens e cores), as formas de disseminação a ideologia, instaurada pelo poder. Justifica-se o tratamento dado, pois com a pós-modernidade e as mudanças sociais resultantes do aparecimento das altas tecnologias, os textos multimodais passam a ocupar lugar importante nas interações discursivas. Anteriormente, os textos eram preferencialmente verbais e, quando construídos com outras semioses, projetavam significações fixas para o visual, diferentes dos textos multimodais que hoje, compostos pelo inter-relacionar do visual e da cor com o verbal, exigindo outras estratégias de produção e processamento da informação. Logo, faz-se necessário analisar de forma crítica a multimodalidade textual, para a representação do feminino que é uma questão social importante, no Brasil. Desde que se entenda que todas as formas de conhecimento são representações mentais, construídas no e pelo discurso, são postuladas três categorias analíticas, a saber: Sociedade, Cognição e Discurso. Este trabalho apresenta resultados parciais de uma pesquisa mais ampla, a respeito do feminino, entendendo-o como uma construção social por discursos públicos e eventos discursivos particulares; tal construção é perpassada pela cultura, valores sócio-cognitivos transmitidos de pai para filho, e pela ideologia imposta pelo poder (valores sócio-cognitivos que atendem aos próprios interesses do poder). A construção textual é vista pela seleção e combinação de fontes diferentes, para a composição co-textual; e pela projeção de diferentes contextos para a complementação sêmica das expressões textuais.

Palavras-chave: anúncios publicitários; contextos e texto multimodal; sociedade, discurso e cognição; análise crítica do discurso.

* Doutora em Letras pela Pontifícia Universidade Católica de São Paulo (1974); professora titular do Departamento de Português da Pontifícia Universidade Católica de São Paulo.E-mail: regcpf@osite.com.br 
Este artigo está situado na Análise do Discurso Crítica (ADC) e tem por tema a relação texto e contexto para a representação do feminino em anúncios publicitários multimodais.

Tem-se por objetivos: 1. Examinar a seleção e a combinação de expressões visuais e verbais, dispostas em anúncios publicitários brasileiros para representação do feminino; 2. Verificar os contextos e suas funções, na produção/compreensão de textos multimodais (visual e verbal).

Tem-se por pressuposto que toda construção textual e a produção de sentidos são elaboradas cognitivamente pelo processamento da informação, na memória de trabalho das pessoas, acessando formas de conhecimento sociais e individuais armazenadas na memória de longo prazo. Sendo assim, é necessário inserir a categoria Cognição junto às categorias Sociedade e Discurso.

O material analisado é constituído de anúncios publicitários brasileiros multimodais impressos. As análises realizadas objetivaram examinar as relações cotextuais entre imagens, cores e expressões verbais, assim como os contextos de sua produção discursiva, para a representação do feminino, no texto.

Os resultados apresentados participam de uma pesquisa mais ampla a respeito das representações ideológicas e culturais do feminino em diferentes discursos.

Tem-se por ponto de partida que sexo e gênero são noções complexas que durante muito tempo foram consideradas sinônimas. Conforme Cháneton (2009), é partir de 1964 que Robert Stollel, apresenta uma diferença entre essas duas noções. Sexo é uma noção ligada à Biologia, definida por gens e hormônios; ao passo que o gênero está relacionado à Sociologia e à Psicologia Social, sendo construído socialmente. Em outros termos, sexo compreende homem e mulher e gênero, o masculino e o feminino que são representações sociais, construídas no e pelo discurso. Assim, desde que se entenda que a ideologia e a cultura guiam essas representações, a pesquisa, que vem sendo realizada, justifica-se, pois é necessário analisar de forma crítica tais representações, para verificar os valores ideológicos contidos nelas, já que eles propiciam a manifestação de crenças sociais preconceituosas, relativas a questões sociais, como a do feminino.

Por outro lado, justifica-se essa pesquisa, pois a mudança social ocorrida com o fenômeno da globalização pôs em uso privilegiado os textos multimodais, principalmente os produzidos com o verbal e o visual (imagens e cores).

Em geral, o letramento esteve direcionado para o texto verbal; por essa razão, o texto multimodal apresenta dificuldades para a sua compreensão, durante a leitura. Sendo assim, urge investigar a produção desses textos.

Kress e van Leewen (1996), preocupados com a multimodalidade, ao tratarem da mudança social ocorrida, durante a globalização, definem o texto multimodal como um produto do discurso, visto como uma ação, que combina o verbal com imagens e cores em uma semiose. Anteriormente, os textos construídos com imagens e cores apresentavam um significado prescrito, como, por exemplo, as placas de trânsito. Com a mudança social, os textos multimodais são colocados em uso por modos semióticos que se inter-relacionam de várias formas; assim, as representações verbais e visuais podem se equivaler, completar-se 
ou mesmo se contradizer. Logo, há uma natureza simbólica nas representações existentes nesses textos, decorrentes de relações providas pelos recursos semióticos que precisam ser investigadas.

Em outros termos, tais representações não são reais, pois o significado criado por um determinado recurso falseia a realidade, na medida em que é uma representação dela, decorrente das intenções e valores ideológicos de quem as representou e em qual situação. Dessa forma, as características gramaticais sintáticas das imagens combinadas com as do verbal são consideradas seleções significativas dentro do conjunto de possibilidades disponíveis nos sistemas gramaticais. Além disso, essas relações gramaticais funcionam ideologicamente, pois as representações contidas nelas são significativas e contribuem para a reprodução de relações de dominação, que a ADC objetiva denunciar.

\section{Considerações teóricas: Análise do Discurso Crítica}

A ADC analisa textos concretos, curtos e longos de interação social e caracteriza-se por uma visão crítica própria e específica para focalizar a relação existente entre a linguagem e a sociedade, além da relação existente entre a própria análise e as práticas sociais e discursivas analisadas. Dessa forma, a ADC focaliza, de modo multi e transdisciplinar, as relações entre sociedade e discurso, tendo por ponto de partida a dialética entre o social e o uso intencional da linguagem: toda mudança nas práticas de linguagem é guiada por mudanças sociais que, ao mesmo tempo, são modificadas pelas práticas de linguagem que vêm sendo postas em uso, pela referida mudança social.

A visão crítica está centrada em problemas sociais e busca analisá-los tanto em relação aos elementos das práticas sociais quanto aos das práticas discursivas, responsáveis pela produção de textos; logo, analisar o discurso de forma crítica requer teorização e descrição tanto dos processos e das estruturas sociais que dão lugar à produção de um texto quanto das estruturas sociais e os processos com os quais os indivíduos ou os grupos sociais, como sujeitos históricos, criam sentidos em sua iteração com os textos.

Para uma visão crítica, três conceitos são importantes, a saber: poder, história e ideologia. Sendo assim, a ACD reconhece a contribuição de todos os aspectos do contexto comunicativo aos significados do texto. (cf. Wodak, 2003)

A ACD apresenta-se com diferentes vertentes, entre elas, a sócio-histórica, a semiótica social e a sócio-cognitiva. Em geral, a visão crítica dessas diferentes vertentes dá atenção à intertextualidade para analisar a significação ideológica do modo sistemático pelo qual os textos se transformam em outros textos.

Este artigo está fundamentado, transdisciplinarmente, na vertente Semiótica Social e na sócio-cognitiva para tratar da dialética do social e o individual ao examinar os recursos semióticos (o que pode ser dito e feito por imagens e por imagens e cores, além de como as coisas que as pessoas dizem e falam com imagens podem ser interpretadas) e de que forma esses recursos manifestam, textualmente, as interpretações da experiência e as formas de interação social, a partir de uma visão analítica crítica do feminino, no Brasil. 
Segundo Fairclough (2005), a transdisciplinaridade compreende um diálogo entre disciplinas ou teorias e métodos que conduz a um desenvolvimento para os pares selecionados, por meio de um processo de apropriação de cada um deles da lógica do outro como recurso para o seu próprio desenvolvimento. Dessa forma, entende-se que as práticas sociais, as discursivas e a produção textual entram na ação discursiva pelos processos cognitivos que constroem as formas de conhecimento sociais e individuais.

A ADC está relacionada à escola de Frankfurt que tem por ponto de partida o marxismo e a perspectiva hallidayana da linguagem.

No que se refere ao marxismo, a ADC aborda o conceito de discurso em relação à ideologia e ao poder, para situá-lo como prática social. Fairclough (1992) situa o discurso em uma perspectiva de poder como hegemonia que é vista como foco de constante luta sobre pontos de maior instabilidade entre classes e blocos para construir, manter ou romper alianças e relações de dominação/subordinação, que assumem formas econômicas, políticas e ideológicas.

No que se refere à perspectiva hallidayana da linguagem, a ADC entende a linguagem humana como um sistema de construção de significados, em uso funcional na interação comunicativa. Para Halliday (1985), a linguagem satisfaz as necessidades humanas e é organizada funcionalmente, respeitando-as e não de forma arbitrária. Por entender que toda linguagem se organiza por um propósito (uma função), o autor estabelece para os componentes funcionais da língua três metafunções: a ideacional, a interpessoal e a textual.

Para a ADC, o texto é produto do discurso. Fairclough (2001) distingue três elementos, relativos aos efeitos constitutivos do texto, decorrentes do discurso: 1. a construção de identidades sociais e de posições para sujeitos sociais e o eu; 2. a construção das relações sociais entre as pessoas; e 3. a construção de sistemas de conhecimento e crenças. Esses três elementos correspondem respectivamente às funções da linguagem postuladas por Halliday (1985): 1. identitária, relativa aos modos pelos quais as identidades sociais são estabelecidas no discurso; 2. relacional, que diz respeito a como as relações sociais entre os participantes do discurso são representadas e negociadas; e 3. ideacional, relativa ao modo pelo qual os textos significam o mundo e seus processos, entidades e relações.

É acrescida, ainda a função textual, relativa a como as informações são trazidas ao primeiro plano ou relegadas a um segundo, apresentadas como conhecidas ou como novas e selecionadas como tema/comentário.

Em breve síntese, com suas vertentes, a ADC busca dar conta da construção de significados tanto como atividade sócio-cognitiva quanto como produção de signos socialmente motivados.

\section{A respeito da vertente semiótica social}

A vertente semiótica social da ADC objetiva tratar da organização de textos multimodais e de seus efeitos constitutivos, propondo uma nova perspectiva semiótica, diferente da tradicional. Para esta vertente, há uma inter-relação, perpassada pela ideologia, 
entre Sociedade e Discurso, de forma que as mudanças sociais produzem mudanças nos discursos e vice-versa; por isso, a partir da década de 1990, ocorre o privilégio dos textos multimodais sobre os verbais, havendo, também, mudança no acesso ao público que além da mídia passa a ser, devido às altas tecnologias, também individual e preferencialmente realizado pelas redes sociais, devido à rapidez e por estarem fora da censura.

Os textos multimodais são complexos. Antes, ao se articular o verbal com outras modalidades, estas apresentavam significações fixas para seus significantes textuais, como por exemplo, as placas de trânsito e as indicações de direção; assim, os letrados focalizavam o verbal para a produção de sentidos. Com as mudanças sociais, os textos multimodais são construídos com diferentes semioses inter-relacionadas, de forma que uma se projeta na outra, modificando-se e construindo significações não fixas para seus significantes textuais.

Kress e van Leewen (1996) propõem uma gramática do design visual, com suas categorias analíticas para a modalidade linguística e a modalidade visual.

Nessa gramática, os autores consideram que a comunicação não ocorre apenas entre pessoas de um mesmo grupo social e, por essa razão, é preciso que uma teoria da multimodalidade forneça explicações no caso das mensagens que exprimem valores e crenças dos outros grupos. Assim, ao tratarem das imagens, os autores entendem que elas se baseiam em padrões de realidade construídos cultural e historicamente e não na correspondência objetiva entre imagem visual e o mundo. Logo, as imagens representam as relações entre pessoas, lugares e as coisas em um complexo conjunto de relações existentes entre as imagens e aqueles que as observam. Para analisar esse conjunto complexo, Kress e van Leewen propõem quatro estratos:

a. o discurso: os discursos desenvolvem-se em contextos sociais específicos que podem ser públicos ou não; por exemplo, contexto familiar e contextos institucionalizados (ex: publicidade, jornal). Os discursos podem ser realizados de diferentes maneiras: um discurso sobre conflito étnico pode ser realizado como parte de uma conversa em um bar ou como um documentário de TV;

b. o design: são maneiras de realizar discursos em contextos determinados, para conceituar a forma dos produtos e dos eventos semióticos, conforme os propósitos e a concepção de quem será a audiência. Assim, um mesmo design pode ser realizado de formas diferentes, segundo o seu contexto de produção;

c. a produção: é a articulação na forma material dos produtos ou eventos para a produção real do texto que exige outros conjuntos complexos de habilidades, como as técnicas, artísticas, manuais e visuais. Neste estrato, a preocupação situa-se nas fontes que possibilitam a produção semiótica;

d. a distribuição: é o acesso ao público pela reprodução dos produtos e dos eventos semióticos. A distribuição não acrescenta sentido ao produto multimodal, mas é o facilitador das funções pragmáticas de preservação e difusão, pois quanto maior e eficiente for o meio de difusão, maior será o consumo pela audiência e, assim, maior disseminação ideológica.

Para Kress e van Leewen (2001), o grau em que a intenção e a interpretação se tornam compatíveis, dependerá do contexto. 
Para os autores, a Semiótica Social objetiva uma análise crítica dos textos multimodais para mostrar "o que é" que está contido nas imagens situadas espacialmente no texto; dessa forma busca responder as perguntas: 1. como as pessoas são representadas? 2. como as pessoas representadas relacionam-se ao observador? 3. como o verbal equivale, complementa ou contradiz o que é captado pelos sentidos, articulando as imagens, as cores e o verbal?

Em outros termos, objetiva, com uma visão analítica crítica, a descrição dos recursos semióticos e o exame da forma desses recursos que manifestam, textualmente, as interpretações da experiência e as modos de interação social.

No que se refere ao verbal, de forma geral, os semioticistas sociais críticos, a partir da gramática sistêmico-funcional de Halliday (1985), preocupam-se com o potencial ideológico do sistema de categorização das representações implícitas em determinados vocábulos, ou seja, com as maneiras particulares de "lexicalizar" a experiência e o modo pelo qual as estruturas gramaticais linguísticas organizam esses vocábulos em estruturas frasais.

No que se refere ao visual, esses semioticistas contribuem para o entendimento dos modos semióticos, nos atuais textos multimodais. Segundo Kress e van Leeuwen (2001) os modos semióticos inter-relacionam-se por três sistemas de significação: o valor funcional, a saliência e a moldura. Estar atento a esses modos propicia conferir os diferentes valores e os distintos eventos contidos na sintaxe textual, pela relação entre o verbal e o visual, para a representação de pessoas e de coisas do mundo.

A Semiótica Social, embora apresente diferenças para seus pesquisadores, segundo Kress e van Leeuwen (2001), deve satisfazer a três requisitos, para ter uma visão crítica, ou seja: 1. representar e comunicar aspectos relevantes das relações sociais que intervêm na comunicação; 2. representar e comunicar os feitos, estados de coisas e de percepções que o produtor quer comunicar; e 3. tornar possível a produção de mensagens que tenham coerência, interna no texto, e, externamente, com aspectos relevantes do entorno semiótico, o "contexto".

\section{A respeito da vertente sócio-cognitiva}

Segundo essa vertente, é necessário postular a inter-relação entre três categorias, para uma análise crítica do discurso: Sociedade, Cognição e Discurso. Van Dijk é o maior representante desta vertente. Segundo o autor (1997), há uma inter-relação entre essas categorias analíticas, de tal forma que uma se define pela outra, pois todas as definições necessárias para uma análise crítica do discurso decorrem das cognições sejam as individuais, situadas na memória episódica ou autobiográfica, sejam as sociais, na memória social.

Dessa forma, segundo a vertente sócio-cognitiva, tem-se por pressuposto que a interação comunicativa pelo discurso decorre das formas individuais e sociais de representação mental do que acontece no mundo, ou seja, formas de conhecimento construídas nos e pelos discursos públicos institucionalizados e por eventos discursivos particulares e manifestadas em textos, produtos do discurso.

Logo, toda a produção/compreensão discursiva perpassa pela cognição. 
Sendo assim, entende-se que:

A Sociedade é definida por grupos sociais, sendo que cada qual é uma reunião de pessoas que têm objetivos, interesses e propósitos em comum. Dessa forma, a estrutura social é vista como um conjunto de papéis sociais (participantes das práticas sociais) selecionados pelos interesses dos membros do grupo, para serem representados, dependendo das situações discursivas. Por exemplo, há grupos sociais ancorados no "trabalho" que selecionam os papéis, entre outros, de professor-aluno, padre-fiel, empresário-funcionários, industrialempregados. Mas, há grupos sociais ancorados na "exploração do outro", apresentando-se pela marginalidade das leis que regem a sociedade atual, de forma a selecionar, por exemplo, os papéis de traficante-drogado, prostituta-cliente, assaltante-vítima. Logo, as práticas sociais variam dependendo de sua estrutura social, devido aos papéis sociais selecionados pelos objetivos, interesses e propósitos do grupo social. Estes guiam o ponto de vista para focalizar o mundo e, a partir daí, representá-lo mentalmente, como forma de conhecimentos sociais.

Como os grupos sociais diferem entre si por terem pontos de vista diferentes, esses grupos estão em constante conflito, pois suas condutas sociais decorrem de suas próprias crenças, em um determinado momento histórico.

A Cognição compreende as formas de conhecimento do grupo social, que em seu conjunto compõem o marco das suas cognições sociais, que são construídas mentalmente, a partir do ponto de vista selecionado pelo grupo. Como o ponto de vista decorre dos objetivos, interesses e propósitos do grupo social, esse, ao ser projetado para focalizar o que acontece no mundo, projeta ao mesmo tempo um conjunto de valores que passam a compor a representação cognitiva, como forma de conhecimento avaliativo, as crenças. Sendo assim, é a partir do que é focalizado pelo ponto de vista (propósitos) que se maximizam ou minimizam e até se cancelam certas propriedades do que é focalizado, de forma a construir conhecimentos que são crenças sociais perpassadas pela ideologia e pela cultural. Estas guiam a construção de formas de conhecimento individuais, decorrentes de experiências pessoais. Dessa forma, todas as formas de conhecimento são crenças por serem construídas com valores culturais e ideológicos, decorrentes do ponto de vista projetado, guiado pelos propósitos.

Segundo Silveira (2009), a ideologia e a cultura são conjuntos de valores contidos nas crenças sociais. A diferença entre elas é que a cultura compreende um conjunto de crenças cujos valores são construídos socialmente pelo vivido e experienciado pelas pessoas; por exemplo, formas de se alimentar, dormir, vestir, cumprimentar e festejar datas. Essas crenças são transmitidas dinamicamente de pai para filho, pois a cada problema social novo a ser resolvido, no cotidiano, ocorre a mudança desses valores, embora tenham raízes sociais históricas. A ideologia origina-se na cultura e é um conjunto de valores, selecionados e modificados pelo poder, a fim de atender a seus próprios interesses, ao impor, intra e extragrupalmente suas crenças, para a discriminação do outro, pois os participantes do poder têm amplo acesso ao público.

Logo, os grupos sociais diferenciam-se entre si por terem crenças diferentes. É, pelos discursos públicos e institucionalizados, que o poder constrói crenças extra-grupais, ou seja, uma unidade imaginária, também designada memória social, que identifica uma nação, em seu contexto histórico. 
Desde que as formas de conhecimento são construções mentais, elas são produzidas e armazenadas na memória das pessoas.

Kintsch e van Dijk (1983) tratam das estratégias de compreensão discursiva, a partir do modelo de memória por armazéns que diferencia a memória de curto prazo, a de médio prazo e a de longo prazo.

A memória de curto prazo é sensorial e dá entrada para a informação que será processada pela memória de trabalho, situada entre a memória de curto prazo e de médio prazo. A memória de trabalho transforma as expressões textuais em sentidos secundários e globais, de forma recursiva, a partir de inferências e explicitações de implícitos textuais. Para tanto, recorre a conhecimentos armazenados na memória de longo prazo, ativando-os para a memória de trabalho, a partir de um contexto cognitivo, ancorado em um modelo de situação.

A memória de longo prazo comporta dois armazéns: o social e o individual. O armazém social, também designado memória semântica, arquiva as representações construídas socialmente, pelos discursos, em sistemas de conhecimentos distintos. Há pelo menos três sistemas gerais de conhecimento: o enciclopédico, conhecimentos de mundo; o simbólico, conhecimentos de códigos semióticos, tais como os visuais (imagens e cores) e os de línguas; e o interacional, conhecimentos de esquemas interacionais comunicativos, tais como atos de fala, gêneros textuaisdiscursivos e quadros enunciativos. Todos eles são perpassados pela cultura e pela ideologia. Tais sistemas organizam as representações mentais tanto no armazém social quanto no individual.

Na memória de longo prazo social estão as formas de conhecimento construídas socialmente, por discursos institucionais, como os da família, da igreja, do Estado, da empresa. Tais discursos são perpassados pela cultura e ideologia; esta é imposta aos membros do poder, para dominar a mente das pessoas, pela discriminação de, por exemplo, raças, gêneros, profissões, nações. A memória de longo prazo individual armazena as formas de conhecimento construídas por experiências individuais, sendo, portanto, autobiográfica. Os conhecimentos sociais guiam os individuais, mas estes, progressivamente, modificam os sociais, devido a modificações sofridas para resolver, socialmente, problemas novos.

Segundo Kintsch e van Dijk, é a ativação dos conhecimentos sociais e dos individuais que explica as razões de nenhum texto ter a mesma leitura nem para o mesmo leitor, em momentos diferentes, nem para leitores diferentes, ainda que haja um certo consenso de leitura entre eles, devido aos conhecimentos sociais.

A memória de médio prazo armazena, durante certo período de tempo, os sentidos produzidos durante o processamento da informação, modificando-os para a construção dos sentidos mais globais que serão armazenados na memória de longo prazo, como formas de conhecimento social ou individual.

O Discurso é definido como uma prática social, selecionada pelo grupo social, cujos textos produtos estão em uso. Van Dijk (1997), ao inserir a categoria Cognição na inter-relação das categorias Sociedade e Discurso, para a ADC, afirma que todas as formas de conhecimento são construídas no e pelo discurso. 
Há discursos públicos e eventos discursivos particulares. Os discursos públicos são definidos como prática social e esquematizadas por um contexto discursivo mental que se define por participantes, suas funções e suas ações. Para van Dijk, há três categorias, para analisar de forma crítica os discursos públicos: Poder, Controle e Acesso.

Cada uma dessas categorias está relacionada extra-textualmente a contextos. Estes se diferenciam dos elementos expressos no texto, cuja construção coesiva intratextual é designada "cotexto". Logo, o "contexto" é visto como o entorno fora da sequência dos elementos presentes no produto textual.

Cada uma das categorias Sociedade, Cognição e Discurso agrupam seus próprios contextos, que são selecionados pelo produtor do texto para combiná-los no produto textual. Na compreensão, os conhecimentos armazenados na memória de longo prazo são ativados para inferir e explicitar significados contextuais. Van Dijk (2012), a fim de explicar as razões das pessoas não produzirem a mesma leitura de um texto, propõe que os contextos são construídos por conhecimentos individuais, os autobiográficos, embora eles sejam guiados pelos sociais.

\section{Textos multimodais publicitários e contextos, na represen- tação do feminino}

Segundo a teoria da multimodalidade, os textos multimodais produzem sentidos múltiplos, pois são produzidos com diferentes semioses. Segundo Kress e van Leeuwen (1996), ao tratarem da semiose visual, os sentidos podem ser realizados pelas línguas e pela comunicação visual. Essas realizações, necessariamente, não se sobrepõem, pois algumas coisas podem ser expressas tanto pelo visual quanto pelo verbal; mas, outras, só pelo visual ou pelo verbal.

\section{A título de exemplificação: anúncios publicitários multi- modais da Duloren}

Foram selecionados três textos de campanhas publicitárias da marca Duloren, publicados em momentos históricos diferentes. 
Texto (1)- campanha da Duloren: contexto histórico Reveillon

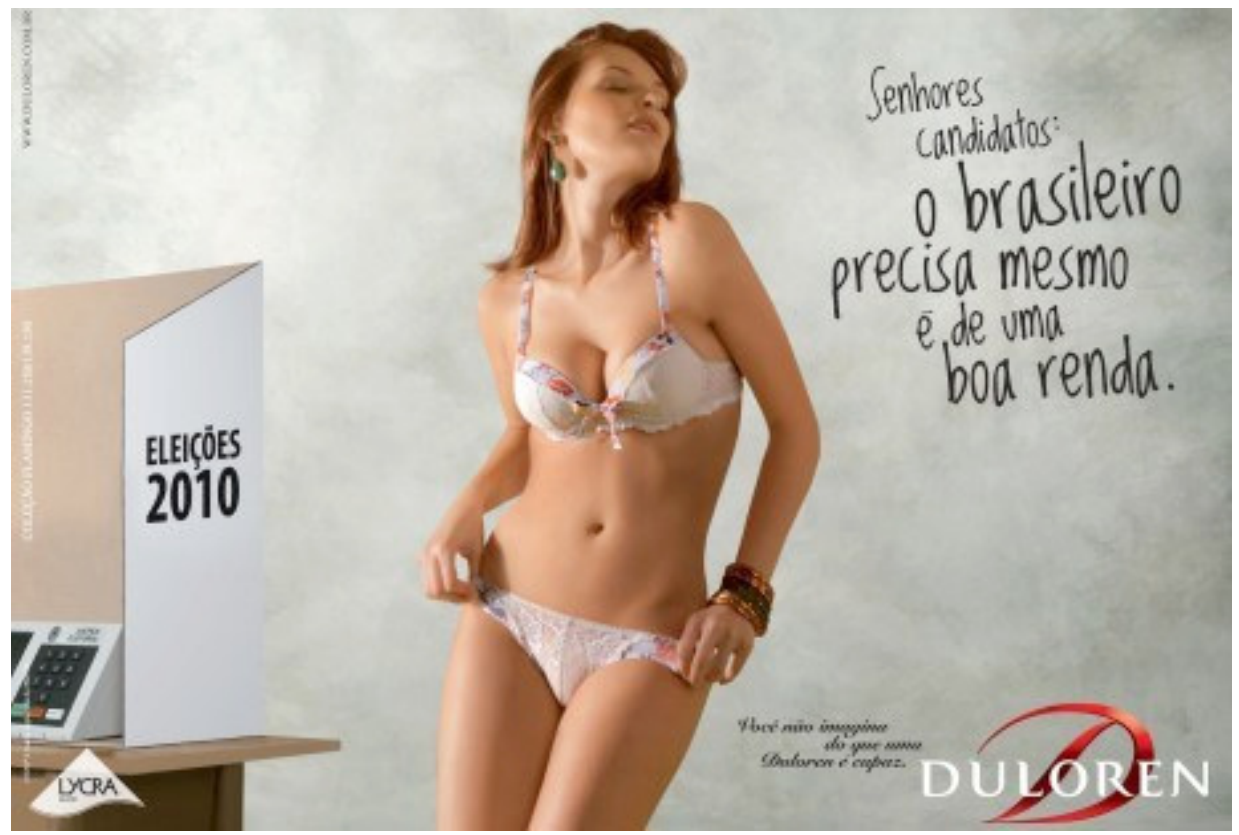

Fonte: http://www.stopper.blogger.com.br/2003_11_01_archive.html

A MG criou para a Duloren, famosa marca de lingeries, uma campanha, veiculada em dezembro na qual a chamada principal é "Prá começar bem o ano, em vez de pular ondinha, eu pulo a cerca"

Texto (2) - campanha da Duloren: contexto histórico eleições de 2010

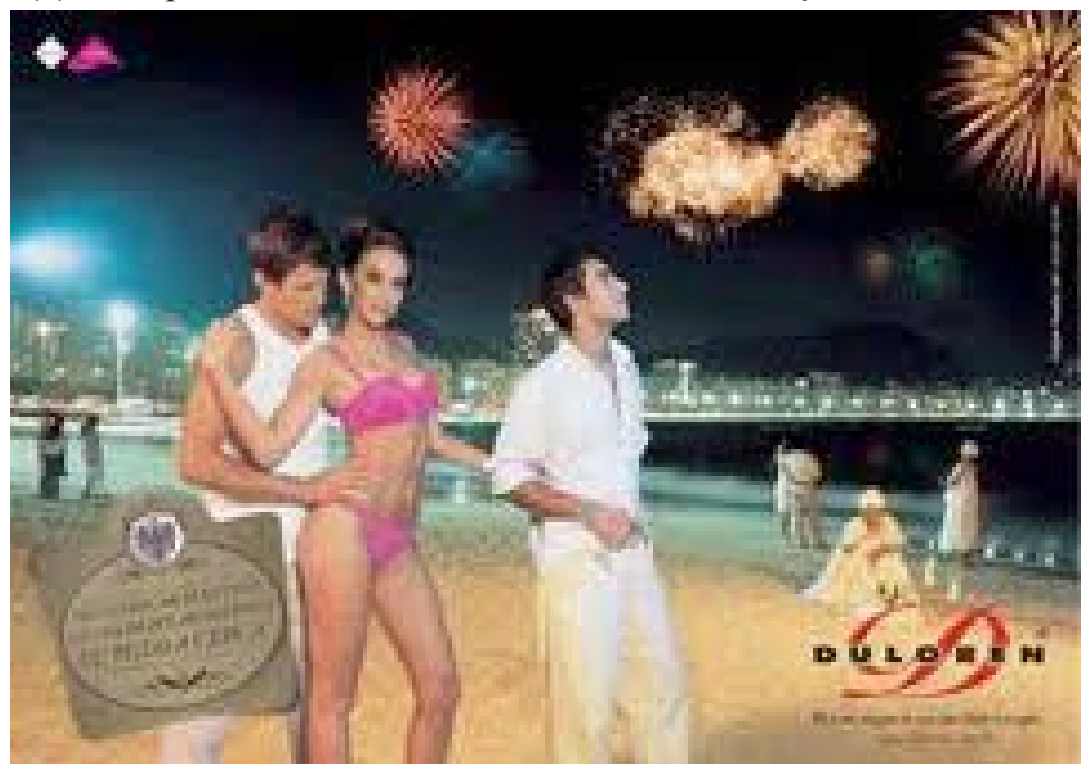


Texto (3) - campanha da Duloren: contexto histórico da pacificação da comunidade do Morro do Alemão, cidade do Rio de Janeiro

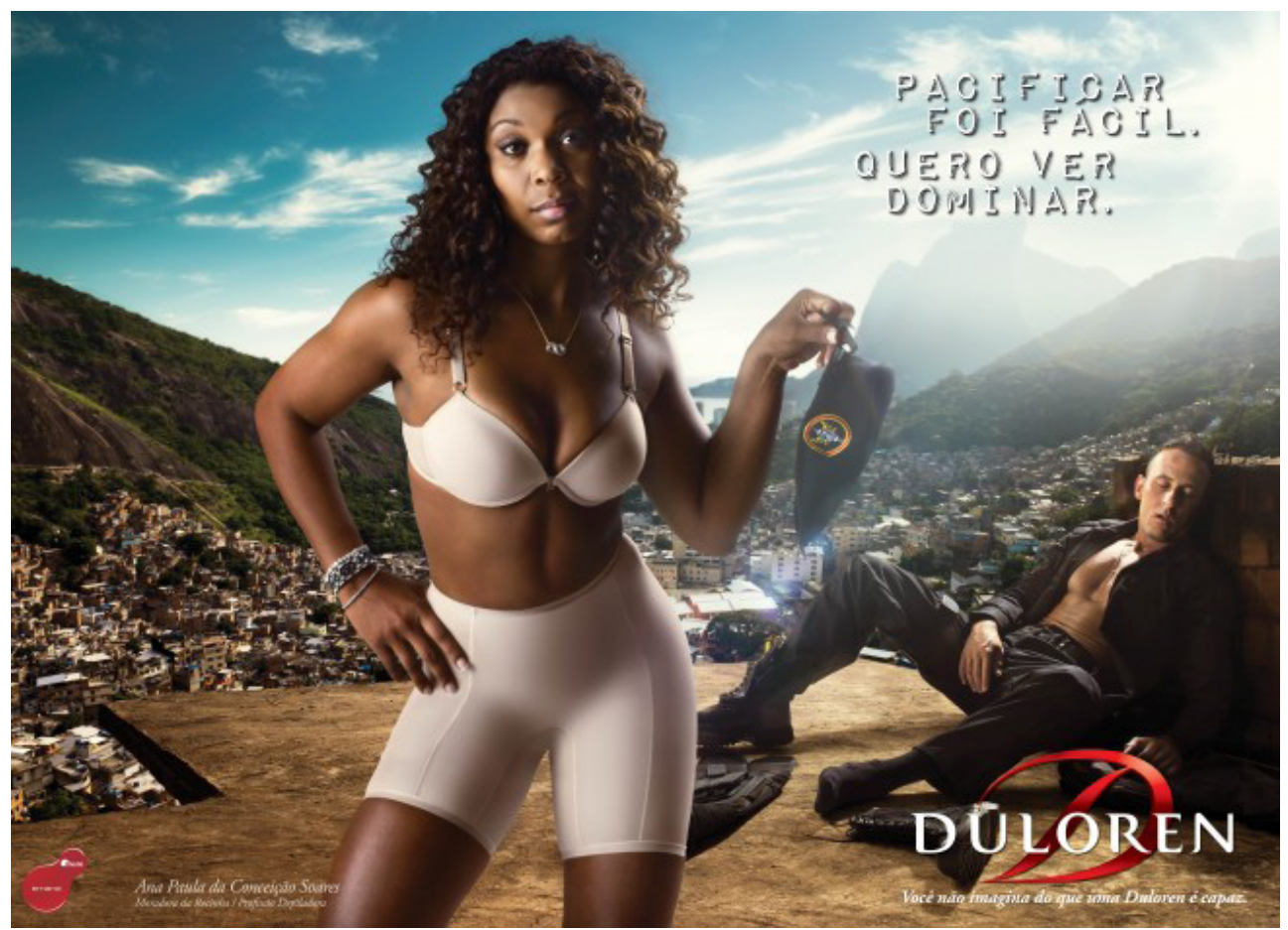

Fonte: http://colunistas.ig.com.br/consumoepropaganda/2012/03/13/du-loren-reestreia-no-complexo-do-alemao/

\section{A composição espacial dos textos exemplificados}

A distribuição espacial do verbal e do visual define a composição do texto multimodal. Kress e van Leeuwen (1996) têm por ponto de partida a gramática sistêmico-funcional de Halliday (1985) e, assim, eles propõem as seguintes categorias, para a análise dessa composição:

- o "dado" e o "novo": os textos, que usam o posicionamento das fontes selecionadas no eixo horizontal, consideram, espacialmente, a direita e a esquerda. Os elementos da esquerda são apresentados como o "dado" (o conhecido socialmente) e os da direita, como o "novo" (desconhecido);

- o real e o ideal: os textos que usam o posicionamento das fontes selecionadas consideram espacialmente, no eixo vertical, o real (embaixo) e o ideal (em cima).

- o valor da informação no centro ou na margem: quando essa seleção ocorre, esse tipo de composição significa que o que é representado no centro é o núcleo da informação e os elementos, que ficam às margens, dependem do central.

- a saliência: dar saliência a elementos cria uma hierarquia de importância entre eles, pois focaliza, em tamanho maior, um elemento da composição; por isso, a hierarquia da 
saliência ancora os demais elementos que compõem o texto, tendo a função principal de integrar os elementos selecionados, na representação do tema textual.

No Texto (1), o verbal expressa crenças das cognições sociais, modificadas pela intenção do produtor (cf. van Dijk, 1997): "Prá começar bem o ano, em vez de pular ondinha, eu pulo a cerca", para representar, metonimicamente, por expressões linguísticas, uma mudança nas crenças sociais: a infidelidade feminina. Expressa, ainda, a imagem com a qual a Duloren quer caracterizar a sua marca: "Você não imagina do que uma Duloren é capaz", logo abaixo da designação da marca: "Duloren".

O visual expressa o ritual realizado por "mães de santo", na praia, no momento da passagem de ano (crença social); e a infidelidade feminina pela imagem de uma moça branca, com expressão sorridente, semi-nua, tendo metade das pernas e pés apagados, com roupas íntimas (calcinha biquine e soutien) de luxo, de cor "rosa choque", com rendas, (relação metafórica com o biquine) da Duloren, em posse de sedução, entre dois rapazes: a moça está de braço dado com o da frente que está distraído observando os fogos de artifício; e abraçada pela cintura pelo de trás que está seduzido por ela, que aceita seu assédio. O céu está iluminado pelos fogos de artifício e embaixo, a praia e as ondas do mar.

Este texto está composto, em sua distribuição espacial, pela combinação dos eixos (horizontal e vertical) com a saliência. No eixo horizontal, à direita, no fundo as mães de santo saltando ondas do mar e a marca da Duloren com a imagem que quer informar o "novo" para o interlocutor: "Duloren, você não imagina do que uma Duloren é capaz". A saliência expande o conteúdo de "capaz", pois traz em tamanho maior e quase centralizada a imagem da infidelidade feminina, representada pela moça branca, delgada, sedutora e dois rapazes: o da frente, distraído, sem notar o assédio de sua companheira, sendo traído, representado pelo verbal "pular a cerca" e o casal de trás, o assediador (o rapaz de trás, abraçando a moça) e a infiel (ela aceita o assédio), vestida com uma Duloren (roupa íntima), em lugar público. Logo, <<uma Duloren é capaz de propiciar a você uma nova e instigante aventura amorosa, ao mesmo tempo que você mantém a sua relação atual, segura, antiga e monótona. >> Sendo assim, os demais elementos dispostos no texto, relativos ao reveillon na praia, tornam-se dependentes do triangulo amoroso, saliente e centralizado, representados pelo verbal ("pular ondinhas" e "pular a cerca"): no fundo, a avenida beira-mar com os prédios iluminados; à margem direita, as baianas e as ondas do mar; à margem esquerda, um casal saltando ondas do mar.

No eixo vertical, em cima o céu iluminado por belos fogos de artifício é o ideal que atrai a atenção do antigo parceiro; embaixo, o trio amoroso, é a concretização da infidelidade feminina, cuja razão é a moça tornar-se sedutora e elegante, vestindo uma lingerie "cor rosa choque", cor da sedução.

No Texto (2), o verbal expressa: "Eleições 2010", "Senhores candidatos o brasileiro precisa mesmo é de uma boa renda", para representar, metonimicamente, por expressões linguísticas, uma mudança nas crenças sociais: mulher ocupar o cargo de presidente brasileiro; assim, a promessa política de uma "boa renda" econômica para garantir o bem-estar dos eleitores é ressemantizada e "boa renda" é o que enfeita as lingeries de luxo, com "lycra", metonimicamente representando o feminino na presidência. 
O visual expressa uma urna eletrônica, situada em uma cabine eleitoral, que representa, metonimicamente, pela imagem, os turnos eleitorais de 2010, no Brasil; expressa, ainda, a beleza e elegância femininas, pela imagem de uma moça branca sofisticada, com expressão indiferente de olhos fechados, com posse de modelo e de sedução, semi-nua, com as pernas e pés apagados, vestida com roupas íntimas de luxo brancas (calcinha biquine e soutien), terminadas com rendas brancas e coloridas. $O$ fundo é de cor neutra acinzentada.

Este texto está composto pela centralização com saliência, em tamanho maior, da imagem da moça que representa o feminino da mulher branca pela beleza elegante e sofisticada. Os demais elementos dependem do centro.

A margem direita está composta no eixo vertical, pela expressão verbal do "novo": em cima, o ideal: "Senhores candidatos, o brasileiro precisa mesmo é de uma boa renda"; embaixo, o real: "Duloren, você não imagina do que uma Duloren é capaz". A saliência centralizada situa o conteúdo de "renda", que abrange duas áreas semânticas: a econômica = maior ganho e a de acessórios = enfeite caro de roupas femininas. Na margem esquerda, o "dado": a metonímia da urna em uma cabine eleitoral, que representa as eleições de 2010, para presidência da república e governadores e que mantém relação com "Senhores candidatos, o brasileiro...".

No Texto (3), o verbal expressa: "Pacificar foi fácil. Quero ver dominar", para representar, metonimicamente, por expressões linguísticas, uma mudança nas crenças sociais: quem pacifica é a polícia, mas quem domina é o rebolado sensual da negra carioca que é a representação racial do feminino.

O visual expressa uma mulher negra, em roupas íntimas, sem rendas (cinta calça e soutien), com expressão indiferente no olhar (olhos abertos e fixos no interlocutor do texto) e no corpo, a posição de rebolado, segurando nas pontas dos dedos, com displicência, o quepe de um policial. Ela tem no pescoço, um cordão que sustenta o símbolo do infinito. No chão, está largado, com os olhos fechados e expressão de cansaço, um soldado vencido, com a camisa aberta, mostrando o peito; no fundo, na parte alta, de um lado o recorte de um lixão e do outro, o recorte de casas pobres da comunidade; embaixo do morro, edifícios altos da cidade do Rio de Janeiro.

Este texto está composto, também, pela centralização com saliência, em tamanho maior e projetado, da imagem de uma moça negra robusta, com o corpo cheio de curvas e bonita, em atitude de desafio e posição de vencedora, segurando com as pontas do dedo o quepe do policial vencido, desmaiado no chão; ela está com cabelos esvoaçantes, com o símbolo do infinito no pescoço e vestida com uma Duloren branca, representação modificada do imaculado pela sensualidade, que é saliente em relação às demais cores das figuras que compõe o cenário da favela do Morro do Alemão. Dessa forma, os demais elementos estão dependentes dela: no fundo (em cima do morro, o lixão e as moradias; embaixo, os prédios a beira mar). Dessa forma a figura da moça expande a expressão "dominar", pelo poder arrasador da sensualidade da mulher negra carioca.

No eixo horizontal, à direita, o "novo", representado na sua composição vertical: no alto, o ideal, situa-se o verbal "Pacificar foi fácil. Quero ver dominar", sobre imagens esfumaçadas do morro (a pobreza) em relação aos prédios, à beira-mar (a riqueza); embaixo, o real, um soldado descomposto, desmaiado e vencido pela força sensual da mulher negra. À esquerda, o "dado", o morro e o lixão. 


\section{Seleção das fontes e combinação semiótica do verbal com o visual}

As fontes são selecionadas de paradigmas que compõem as partes do texto multimodal e podem ser vistas como interagindo e afetando umas às outras, conforme são combinadas na composição do todo (texto produto). É interessante observar que a noção de seleção, para a ACD, não implica a consciência do sujeito-produtor, devido à disseminação da ideologia, que instaura a dominação pelo Poder.

No Texto (1), as fontes são selecionadas de um paradigma festivo do reveillon brasileiro, guiado por rituais de religião afro-brasileira e um paradigma de relações amorosas entre homens e mulheres.

- paradigma social festivo: a fonte selecionada é comemoração do reveillon que tem, na praia brasileira, a influência religiosa afro-brasileira. Para essa comemoração, foram selecionados casais e mães de santo, todos vestidos de branco. À meia-noite, soltam fogos espetaculares, os casais pulam sete ondas, para dar sorte no ano que entra, e as mães de santo entregam, nas águas do mar, flores para Iemanjá, a rainha do mar.

A seleção da fonte, nesse paradigma, completa pelo visual o conteúdo sêmico da expressão verbal "pular sete ondinhas", cujo morfema diminutivo complementa, também, pela inserção de um certo tom irônico.

- paradigma de relações amorosas entre casais: a fonte selecionada é a infidelidade, que nas cognições sociais é atribuída ao masculino, mas que no texto (2) está modificada pela projeção no feminino, representada pela saliência visual do triângulo amoroso, originado pelo uso de uma lingerie Duloren, cor "rosa choque" e não branca; assim, representa-se o feminino: pela sedução causada pelo uso de uma Duloren e pela aceitação do assédio de outro parceiro. A seleção dessa fonte tem a intenção de completar pelo visual o conteúdo sêmico do verbal "pular a cerca" que representa os limites do compromisso amoroso, nas cognições sociais.

No Texto (2), as fontes são selecionadas de dois paradigmas: um político, do qual é selecionada a eleição para presidência de 2010, com os candidatos Dilma e Serra, no segundo turno; o outro, um paradigma social da mulher, do qual são selecionados a beleza e a elegância da mulher branca, ancoradas no luxo.

A seleção dessas fontes tem a intenção de completar pelo visual o conteúdo sêmico do verbal "senhores candidatos, o brasileiro precisa mesmo de uma boa renda" $=<<$ o brasileiro precisa mesmo de uma mulher presidente $>>$, metonimicamente representada, por "uma Duloren", ou seja, pela elegância e beleza devido às suas roupas íntimas, terminadas luxuosamente com rendas caras e de excelente qualidade, como é uma Duloren.

No Texto (3), há seleção de fontes em dois paradigmas, de cognições sociais típicos da cidade do Rio de Janeiro: um paradigma policial: seleção do poder do policial para garantir a paz da população, usando o seu uniforme, enquanto está em serviço, principalmente, nas 
favelas que se situam em morros, onde se escondem os bandidos que dominam o tráfico de armas e de drogas; e um o paradigma dos moradores das comunidades: seleção do poder de sedução sensual da mulher negra sobre o masculino. A seleção dessas fontes tem a intenção de completar pelo visual, o verbal "Pacificar foi fácil. Quero ver dominar". "Pacificar" é complementado pela figura do policial; "dominar", pela figura da moça negra, em atitude de desafio olhando diretamente nos olhos do interlocutor, com a aparência de vencedora, em pose de rebolado, com o quepe do policial nos dedos e o policial desalinhado, desmaiado no chão.

A relação entre o visual e o verbal é complementada com "Você não imagina do que uma Duloren é capaz" =<< quem domina as forças pacificadoras das comunidades dos morros do Rio de Janeiro é o poder de sedução sensual da mulher negra, reforçado e ampliado pelo uso de uma Duloren".

\section{Os contextos no anúncio publicitário}

Desde que se insira a categoria Cognição às categorias Sociedade e Discurso, todos os contextos são entorno do texto produto, enquanto formas de representação mental, ou seja, formas de conhecimento sociais e individuais.

Dessa forma, os sentidos produzidos são dependentes dos contextos ativados da memória de longo prazo para a memória de trabalho, a partir da percepção de como o texto multimodal está composto, a fim de serem produzidos os sentidos.

Nos textos exemplificados, são prováveis pela sua composição, os seguintes contextos:

\section{Contexto social}

Este contexto é formado pelos grupos sociais, selecionados de fontes que compõem as cognições sociais.

No Texto (1), as identidades dos papéis sociais do compromisso amoroso são modificadas, pois o feminino é representado pela infidelidade, que ocasiona o triângulo amoroso pelo "pular a cerca"; o papel social do masculino, nesse compromisso é mantido: o machismo, pelo assédio do membro externo da relação e pela segurança do membro interno. As identidades religiosas afro-brasileiras são mantidas: a mãe de santo tem a função de estabelecer relações entre o humano e o divino; os crentes têm a função de seguir as mães de santo, em rituais específicos: no reveillon, elas oferecem flores a Iemanjá; os crentes pulam sete ondas.

A representação do feminino pela infidelidade é ideológica, pois tem valor negativo extra-grupal na sociedade brasileira cujas raízes históricas situam-se no discurso eclesiástico; embora, no grupo minoritário das feministas, a mulher tenha tanto direito de ser infiel quanto o homem. 
No Texto (2), nas identidades sociais do grupo político, o papel do masculino é ocupado pelo feminino, para representar a presidência brasileira, embora os papéis de candidatos e eleitores sejam mantidos, conforme as cognições sociais. O papel de eleitor é representado pelo visual, cabine de votação com sua urna eleitoral.

No Texto (3), - as identidades sociais dos dois grupos sociais estão modificadas. No policial, o papel do soldado é de dominar a marginalidade (traficantes de armas e drogas), no morro carioca. Esse papel está modificado, pois o policial é representado como dominado. No grupo social dos moradores de comunidades, o papel da mulher negra está modificado, pois a sua função de ser protegida pelo policial é representada como pela do dominador (o poder da sensualidade negra que atrai os olhares masculinos pelo rebolado de seu corpo flexível, robusto e curvilíneo, das passistas, rainha de bateria e porta-bandeira, nas escolas de samba).

\section{Contexto discursivo}

O discurso publicitário, visto como uma prática social que, segundo a vertente sóciocognitiva, defini-se por um esquema cognitivo que é organizado pelas categorias Poder, Controle e Acesso, cada qual com seus participantes, funções e ações. O discurso publicitário tem seu contexto discursivo ancorado na ação de anunciar um produto novo, sendo ela modalizada pelo propósito de transformar o interlocutor em consumidor.

O Poder é representado pelos donos da empresa que tomam a decisão de anunciar seus produtos. Nos textos exemplificados, os donos da empresa Durlorem que decidem anunciar as suas lingeries, para vender mais no mercado. Para tanto, contratam uma agência de publicidade.

O Controle é representado pelos participantes da agência de publicidade que têm por propósito produzir o anúncio publicitário que propicie a maior venda do produto anunciado. Para tanto, recorrem à pesquisa de mercado (marketing) a fim de saber o que falta para os consumidores do produto anunciado. Dessa forma, os participantes especialistas, que executam as ordens do poder, produzem o anúncio, guiados por três exigências: criar a necessidade de consumo, prometer que o consumo do produto anunciado satisfaz essa necessidade com pouco custo e em pouco tempo.

O Acesso é representado pelos participantes que distribuem o anúncio para que ele tenha acesso à audiência selecionada para ser atingida (auditório universal ou particular). É o acesso ao público que garante, ao poder, a realização das funções pragmáticas de preservação e distribuição, de forma a garantir maior disseminação ideológica. Os anúncios selecionados foram publicados em revistas de grande circulação e continuam sendo divulgados pela Internet.

\section{Contexto cognitivo}

O contexto cognitivo é composto pelas crenças sociais da audiência, de forma a produzir um entorno relativo às identidades sociais e suas relações entre as pessoas. No Texto (1), segundo as cognições sociais, ideologicamente, a infidelidade masculina é representada 
com valor positivo, devido ao machismo brasileiro e a infidelidade feminina, com valor negativo, propiciando a sua discriminação social. Nesse texto, há, portanto, uma relevância, com alto grau de informatividade, que obriga o interlocutor a mudar o seu contexto cognitivo que vinha sendo construído com os conhecimentos sociais ativados da memória de longo prazo: o verbal e o visual representam a infidelidade feminina, ocasionada pelo uso de uma Duloren que dá, à mulher, o poder de atração. Dessa forma, o contexto cognitivo cria o entorno para definir os modos pelos quais as identidades sociais são estabelecidas no discurso: a função textual de tema (a infidelidade feminina, como o "novo") e comentários (uma Duloren é capaz de dar o poder de sedução à mulher, tornando-a sensual e atraente para satisfazer seu desejo de relação amorosa nova e instigante).

No Texto (2), conforme as crenças sociais ativadas, para compor o contexto cognitivo, nas identidades sociais de candidato a cargo e eleitores, o presidente brasileiro é representado pelo masculino. Esse texto apresenta uma relevância que obriga o interlocutor a mudar o seu contexto cognitivo que vinha sendo construído com os conhecimentos sociais ativados da memória de longo prazo: o verbal e o visual representam o grupo social político, tematizado pela presidência feminina (representada metonimicamente por "uma boa renda" $=<<$ elegância sofisticada $>>$ ) que participa do grupo social da mulher cujas funções identitárias são mantidas.

No Texto (3), segundo as crenças sociais, a polícia é representada pelo poder de domínio da marginalidade e que, no momento atual, é necessária, pois tal marginalidade causa violência social que precisa ser anulada pelo poder político, para a realização de competições atléticas internacionais. No texto (3), a representação textual do policial, dominado pela mulher negra, tem um grau alto de informatividade, pois, com relevância, modifica a identidade do papel social de policial $=$ dominado pelo poder de sedução sensual erótico da mulher negra, a dominadora. Tal relevância o interlocutor a mudar o seu contexto cognitivo que vinha sendo construído com os conhecimentos sociais, a respeito da pacificação da comunidade do Morro do Alemão, pelo domínio da força policial e que foi muito divulgada pela mídia. Logo, o feminino é representado pelo erotismo, como forma de discriminação do valor de produtividade social e econômica da mulher negra brasileira, devido ao machismo e ao racismo brasileiros: a função textual de tema (o poder de domínio do erotismo da mulher negra, moradora da comunidade do Morro do Alemão) e o comentário (a polícia pacifica pela força, a negra do morro domina todos e mesmo a polícia pelo poder de seu erotismo). Esse domínio erótico é expresso, metonimicamente, pelo verbal: "quero ver dominar", que é expandido pelo visual: a mulher negra muito erótica, resultado de vestir o seu corpo belo, robusto e curvilíneo, muito bem delineado pela lycra do soutien e da cinta calça da Duloren, que diferentes das lingeries da mulher branca, não têm rendas, pois o poder aquisitivo é baixo. Este, também é representado pelo visual que focaliza como cenário o lixão e as moradias pobres do morro carioca.

\section{Contexto de linguagem}

Este contexto decorre do conhecimento que se tem a respeito dos diferentes usos da linguagem, a partir de variedades e variações lingüísticas, selecionadas para a composição do texto, na prática discursiva. Nos grupos sociais de baixa escolaridade, o uso é designado variedade nativa de uso oral; nos grupos sociais de alta escolaridade há duas variedades linguísticas: a oral, 
variedade padrão-real; e a escrita, variedade padrão normativa, aprendida na Escola.

No Texto (1), o verbal é expresso por: "pular ondinha", cujo morfema diminutivo tem a função de inserir modalmente a ironia, para designar um ritual de reveillon; e "pular a cerca" que é uma expressão idiomática brasileira para designar a infidelidade conjugal feminina, expandida pelo visual; a designação "cerca" é ressemantizada e contém $<<$ limites impostos pela relação conjungal $>$. A expressões linguísticas selecionadas são da variação coloquial do padrão-real, que representa o grupo social dos participantes: "Prá começar bem o ano, em vez de pular ondinha, eu pulo a cerca".

Esse texto traz representadas em língua duas sequências dialógicas:

- a primeira sequência dialógica: diálogo da moça com seus interlocutores textuaisdiscursivos, que lêem o anúncio ("eu"- quem fala para os interlocutores).

- a segunda sequência dialógica: diálogo dos fabricantes da Duloren com os interlocutores textuais-discursivos: "Você não imagina do que uma Duloren é capaz" $=<<$ comprem lingeries Dulorem que elas são capazes de produzirem mudanças sociais, devido à valorização da atração feminina $>$.

No Texto (2), verbal é representado pelas expressões "boa renda" para focalizar o tema textual, "do que uma Duloren é capaz". O visual complementa o conteúdo sêmico do verbal, pela representação de uma mulher branca elegante e sofisticada, vestida com uma Duloren, com belas e luxuosas rendas. As expressões linguísticas selecionadas são da variação coloquial do padrão-real e verbalizam uma mudança social. Dessa forma, ocorre a ressemantização da expressão "boa renda" que compõe o paradigma lexical da política econômica brasileira, inserindo o sentido de "presidenta" $<<$ mulher eleita para o cargo de presidente $>>$, complementado com o valor positivo.

Esse texto traz representado em língua duas sequências dialógicas:

- a primeira sequência dialógica: diálogo dos participantes da Duloren com os candidatos à eleição para presidente, em 2010. "Senhores candidatos: o brasileiro precisa mesmo é de uma boa renda";

- a segunda sequência dialógica: diálogo dos fabricantes da Duloren com os interlocutores textuais-discursivos: "Você não imagina do que uma Duloren é capaz" $=<<$ comprem lingeries Dulorem que elas são capazes de produzirem mudanças sociais, devido à valorização do feminino>>.

No Texto (3), o verbal representado pelas expressões "Pacificar foi fácil. Quero ver dominar" para focalizar o tema textual $<<$ o poder de domínio da negra brasileira, devido ao seu poder de domínio do masculino, pela sensualidade erótica, ampliada pelo uso de uma Duloren $>>$ = "do que uma Duloren é capaz". O visual complementa o conteúdo sêmico do verbal, pela representação de uma mulher negra, curvilínea e erótica, com atitude de desafio e de domínio, em posse de rebolado, tendo o símbolo do infinito no pescoço, vestida com uma Dulorem, de lycra sem rendas, dando formas bem marcadas ao corpo feminino. As expressões linguísticas selecionadas são da variedade nativa do grupo social de comunidades cariocas, onde o funk é privilegiado. A designação "dominar" está intertextualizada com a letra da 
música funk "Tá dominado": "Rebola levantando o dedinho; rebola. rebola dominando esse corpinho. Então ah, eu quero ver tu dominar. Tá tudo dominado, dominado ...". Dessa forma, ocorre a ressemantização da expressão "dominar" que compõe o paradigma lexical da gíria dos habitantes de comunidades cariocas, inserindo o sentido de poder de domínio do rebolado da mulher negra do morro carioca.

Esse texto traz representado, pelo verbal, duas sequências dialógicas:

- a primeira sequência dialógica: diálogo da mulher negra com seu interlocutor ( ela olha fixo em quem iterage com o texto) e com o policial pacificador "Pacificar foi fácil. Quero ver dominar".

- a segunda sequência dialógica: diálogo dos fabricantes da Duloren com os interlocutores textuais-discursivos: "Você não imagina do que uma Duloren é capaz" $=<<$ comprem lingeries Dulorem que elas são capazes de produzirem mudanças sociais, devido à valorização do erotismo feminino>>.

\section{Contexto histórico}

O contexto histórico é construído com a ativação de conhecimentos que situam cronologicamente os eventos no mundo.

No Texto (1), o tempo cronológico selecionado é o reveillon, tendo por cenário, uma praia brasileira.

No Texto (2), o tempo cronológico selecionado é a eleição de 2010 para a presidência brasileira, tendo por cenário, uma cabine eleitoral com a sua urna eletrônica.

No Texto (3), o tempo cronológico selecionado é a invasão e pacificação do Morro do Alemão, na cidade do Rio de Janeiro, pela polícia, anteriormente dominado pelos chefes do tráfico de drogas e de armas.

Os resultados das análises apresentadas indicam que o feminino é valorizado em sua representação discursiva pelo poder de sedução da mulher branca, representada na composição do verbal com o visual por: poder de atração sensual, representado pela infidelidade feminina em compromissos amorosos; e poder de ação e decisão políticas, representado pela beleza feminina elegante e sofisticada. O poder da mulher negra é de domínio do masculino pela sensualidade erótica. Essas representações são ideológicas, na medida que discriminam socialmente a mulher brasileira: a. pelo poder econômico - a branca, alto poder aquisitivo (beleza sofisticada) e a negra, baixo poder aquisitivo (beleza erótica); b. pelas funções de sedução do masculino, quando o feminino, hoje, vem ocupando o papel de chefe de família, devido à sua competência e produtividade no trabalho.

Esses resultados indicam, também, que o anúncio publicitário é um gênero textual. Os textos diferenciam entre si pelos gêneros discursivos, decorrentes dos usos que esses textos 
têm em sociedade. Dessa forma, os gêneros textuais são vistos como formas discursivas, ligadas às esferas da vida social.

Segundo estudiosos do gênero, as pesquisas devem ser realizadas para responder a seguinte pergunta: Por que os membros discursivos constroem textos da maneira como são feitos?

A inserção da categoria Cognição para o exame de contextos na produção de sentidos e para a composição do produto textual indica que o anúncio publicitário é um gênero textual construído com uma sequência textual explicativa incrustada em uma sequência argumentativa, de forma a combinar o visual com o verbal.

Em síntese, o anúncio publicitário é um gênero textual que apresenta uma relevância cognitiva em relação às cognições sociais, devido à mudança de papeis das práticas sociais, a fim de anunciar o produto novo a ser consumido. As expressões verbais são selecionadas da variedade/variação linguísticas, representativas das pessoas representadas, no visual, como participantes, intencionalmente, selecionados de grupos sociais. Assim, controi-se o "novo" em relação ao "dado" e tematiza-se o produto anunciado. Os comentários são construídos por argumentos de legimitidade, pois são selecionados das cognições sociais (o "dado", o conhecido) e modificados pelas intenções do produtor, guiadas pelo macroato de fala discursivo: fazer consumir. Trata-se de uma estratégia de produção que caracteriza a prática discursiva da construção do texto que está em uso nas práticas sociais da audiência.

Para concluir, acredita-se que os objetivos propostos tenham sido cumpridos, pois os resultados apresentados indicam que tratar de textos multimodais (anúncios publicitários), pelo enfoque dos contextos, de forma a considerar a categoria Cognição, com as categorias Sociedade e Discurso, contribui para descrever tanto aspectos da composição textual da modalidade verbal com a visual, assim como estratégias de compreensão, aplicadas para a produção de sentidos. Logo, os sentidos produzidos são representações mentais que constroem, socialmente, as crenças contidas nas cognições sociais grupais e extra-grupais, perpassadas historicamente pela cultura e pela ideologia. Tais crenças são construídas no e pelo discurso, cujo produto é o texto.

Os resultados apresentados indicam, também, que os elementos selecionados pelo produtor participam de sistemas de conhecimento (simbólico, interacional e enciclopédico), armazenados na memória de longo prazo das pessoas, após terem sido processados por elas. Todavia, é necessário considerar que a ativação do armazenado nem sempre é consciente, pois a ideologia do Poder, que tem acesso ao público, pelos discursos, passa a dominar a mente das pessoas, levando-as a sustentar essa ideologia por sua reprodução textual, no e pelo discurso.

Nesse sentido, conclui-se que, na interação comunicativa entre as pessoas, todas as práticas sociais e os textos estão inter-relacionados, de algum modo, às formas de conhecimento, representações mentais sociais e individuais que são crenças originadas no social. Logo, são elas que guiam as ações das pessoas no mundo, tanto para manter quanto para modificar, dinamicamente, a memória social.

Os resultados apresentados abrem novas perspectivas de pesquisa para se tratar de outros tipos de contextos implicados nos textos multimodais publicitários e de textos multimodais de outros discursos. 


\section{REFERÊNCIAS}

FAIRCLOUGH, N. Discourse and social change. Cambridge: Polity Presse, 1992.

FAIRCLOUGH, N. Critical discourse analysis in transdisciplinary research. In: A new agenda in (critical) discourse analysis: theory, methodology and interdisciplinarity. Amsterdan/Philadelphia: J. Benjamin Publishing Company, 2005.

FAIRCLOUGH, N. Language and globalization. London: Routledge, 2006.

Discurso e mudança social. [Trad. Izabel Magalhães]. Brasília-DF: Edunb, 2001.

HALLIDAY, M. An introduction to funcional Grammar. Baltimore: Edward Arnold, 1985.

KINTSCH, W. ; VAN DIJK, Teun. Strategies discoursive comprehension. London: Academic Press, 1983.

KRESS, G. ; VAN LEEWEN, T. Multimodal discourse: the modes and media of contemporary communication. London: Arnould, 2001.

Reading images: the grammar of visual design. London: Routledge, 1996.

POTTIER, B. Linguistique générale. Théorie et description. Paris: Klincksiek, 1974.

SILVEIRA, R. C. P. da. Um novo olhar para as narrativas de humor: os sentidos no cotidiano e na cultura. O texto em perspectiva. PIRES, L. C. ; BEZERRA, A. ; CARDOSO, D. (Orgs). Aracaju-SE: UFA, 2009.

VAN DIJK, T. Racismo y análisis crítico de los médios. Madrid: Paidós, 1997.

Sociedade e contexto. [Trad. Rodolfo Ilari], S. Paulo: Cortez, 2012.

Sociedad y discurso- cómo influen los contextos sociales sobre el texto y la conversación. [ Trad. Elza Ghio], Barcelona: Gedisa, 2011.

WODAK, R. De qué trata el análisis crítico del discurso (ACD). Métodos de análisis crítico del discurso. WODAK, R. ; MEYER, M. (Orgs). [Trad. Tomás Fernandez Aúz e Beatriz Eguibar], Barcelona:Gedisa, 2003. 
